\title{
Temperatura e embalagens na conservação pós-colheita de Eugenia uvalha Cambess - Mirtaceae
}

\author{
Temperature and packs in post harvest conservation of Eugenia \\ uvalha Cambess - Mirtaceae
}

Silvana de Paula Quintão Scalon ${ }^{1} \quad$ Paolo Dell’Olio $^{2}$ José Luiz Fornasieri ${ }^{3}$

\section{- NOTA -}

\section{RESUMO}

Esse trabalho foi desenvolvido com o objetivo de avaliar o efeito de embalagens para modificar a atmosfera $e$ a temperatura de armazenamento sobre a perda de massa e sobre os atributos de qualidade da uvaia (Eugenia uvallha). No início do experimento e após $1,2,3$ e 4 dias de armazenamento, à temperatura ambiente $\left(32^{\circ} \mathrm{C}\right)$ e $3,6,9, e$ 12 dias de armazenamento, sob refrigeração $\left(13^{\circ} \mathrm{C}\right)$, as uvaias foram pesadas e avaliadas quanto ao teor de sólidos solúveis totais (SST), acidez total titulável (ATT) e pH. O experimento foi conduzido em delineamento inteiramente casualizado em esquema fatorial 2 (temperaturas) $\times 3$ (embalagens) $\times 5$ (dias de armazenamentos) com três repetições de 20 uvaias. A perda média de massa das uvaias armazenadas sem embalagem (8,46\%) foi 2,3 e 19,5 vezes maior que daquelas embaladas em PVC (3,71\%) e "CF film" (0,44\%), respectivamente. As uvaias embaladas conservaram a aparência e qualidade para comercialização quando armazenadas até quatro dias a $30^{\circ} \mathrm{C}$ e 12 dias em refrigerador. SST, ATT e pH variaram durante o armazenamento.

Palavras-chave: armazenamento, refrigeração, perda de massa.

\section{ABSTRACT}

This work was carried out with the objective of evaluating the effect of two kinds of packs to modify atmosphere and storage temperature on fresh weight loss and on quality attributes of "uvaias" (Eugenia uvalha). At the beginning of the experiment and after 1, 2, 3 and 4 days of storage at environment conditions and 3, 6, 9 and 12 days of storage under refrigeration $\left(13^{\circ} \mathrm{C}\right)$, “uvaia” fruits were weighted and evaluated concerning soluble solid contents (SSC), total titritable acidity (TTA) and $\mathrm{pH}$. The experiment was carried out in a complete randomized design in 2 (temperatures) $\times 3$ (packs) $\times 5$ (days of storage) factorial scheme with three replications with 20 " uvaias". Average fresh weight loss of storage "uvaias" without packing (8,46\%) were 2,3 and 19,5 times bigger than those packed in PVC (3.71\%) and CF Film (0.44\%), respectively. Packed "uvaias" keep appearance and quality for commercialization when stored until four days under $30^{\circ} \mathrm{C}$ and 12 days in $13^{\circ} \mathrm{C}$. SSC, TTA and $\mathrm{pH}$ varied during storage.

Key words: storage, refrigeration, fresh weigtht.

A uvaia (Eugenia uvalha Cambess) é uma espécie arbórea da família Mirtaceae também conhecida como uvalha, uvaia-do-mato, uvalheira. Os frutos podem ser consumidos in natura, na forma de sucos, geléias e doce em pasta (ANDERSEN \& ANDERSEN, 1988) e apresentam umidade em torno de $90,7 \%$; teor

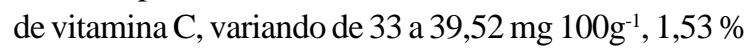

${ }^{1}$ Biólogo, Doutor, Universidade Federal do Mato Grosso do Sul (UFMS), Rodovia Dourados/Itahum, Km 12, Bairro Rural, 79804970, Dourados, MS, Brasil. E-mail sscalon@ceud.ufms.br

${ }^{2}$ Acadêmico do Curso de Agronomia, Universidade Torino, Itália.

${ }^{3}$ Engenheiro Agrônomo, Doutor, UFMS. 
de acidez, sólidos solúveis de 7,5Brix e relação SST/ ATT de 4,90 (CARVALHO, 1988; DONADIO, 1997).

A qualidade dos frutos é atribuída ao seu tamanho e forma e à cor da casca. Esses fatores, associados à composição físico-química da polpa, oferecem aos frutos e aos produtos deles obtidos a qualidade organoléptica e nutricional, responsáveis pela aceitação definitiva desses no mercado. Como para a maioria dos frutos o conteúdo de água situa-se entre 80-95\%, sua perda resultará em enrugamento dos tecidos, amaciamento da polpa e perda de peso, característica essa muito importante para os frutos comercializados com base em peso.

Segundo CHITARRA \& CHITARRA (1990a), modificação da atmosfera no armazenamento de frutos e hortaliças, complementando ou substituindo a refrigeração é uma técnica que tem sido usada nas últimas décadas. Essa técnica tem conseguido prolongar a vida pós-colheita dos frutos, minimizando as perdas de massa, reduzindo a taxa respiratória e produção de etileno, sem provocar alterações na cor, acidez titulável, pH, sólidos solúveis e conteúdo de ácido ascórbico conforme observado em kiwi (MAZARO et al., 2000); morango ( LI \& KADER, 1989; SCALON et al., 1996); manga (MELO NETO et al., 1999), acerola (ALVES, 1993), dentre outras frutas.

Como são raras as informações referentes à conservação pós-colheita da uvaia, este trabalho foi desenvolvido com o objetivo de avaliar o efeito de dois tipos de embalagens para modificar a atmosfera e temperatura de armazenamento sobre a perda de massa e os atributos de qualidade como sólidos solúveis totais, acidez total titulável e $\mathrm{pH}$.

As uvaias foram colhidas pela manhã no pomar da Universidade Federal do Mato Grosso do Sul - MS, selecionadas por tamanho e cor e acondicionadas em bandejas de isopor 15 x $12 \mathrm{~cm}$. As bandejas foram pesadas, embaladas e armazenadas em refrigerador a $13 \pm 2^{\circ} \mathrm{C}$ e à temperatura ambiente a 30 $\pm 2^{\circ} \mathrm{C}$. Para modificação da atmosfera, foram utilizadas as embalagens de PVC laminado (Cloreto de polivinila) e CF film (filme conservante, embalagem plástica contendo absorvente de etileno), e bandejas sem embalagem que serviram como tratamento testemunha.

As uvaias foram pesadas e avaliadas quanto ao teor de sólidos solúveis totais (SST), acidez total titulável (ATT) e pH segundo AOAC (1992), no início do experimento; após 1, 2, 3 e 4 dias de armazenamento à temperatura ambiente; 3, 6, 9, e 12 dias de armazenamento, sob refrigeração, totalizando cinco épocas.
Durante as avaliações, foram realizadas avaliações quanto à aparência dos frutos, baseadas na escala de notas: $0=$ frutos perfeitos; $1=$ frutos sem brilho ; 2 = frutos com murcha leve; 3 = frutos com murcha acentuada e impróprios para comercialização; 4 = frutos com mofo e murcha acentuada, e impróprios para comercialização

O experimento foi conduzido em delineamento inteiramente casualizado em esquema fatorial 2 (temperaturas) x 3 (embalagens) x 5 (dias de armazenamento) com três repetições e unidade experimental composta por uma bandeja com 20 uvaias. Os dados foram avaliados pelo teste $\mathrm{F}$ e a médias comparadas pelo teste de Tukey a 5\% de probabilidade de erro, sendo realizada análise de regressão para os efeitos dos dias de armazenamento sobre a perda de massa.

Não houve interação tripla significativa entre os fatores em estudo para nenhuma das características avaliadas. Para as duas condições de armazenamento e embalagens, as uvaias apresentaram um comportamento linear de perda de massa ao longo dos dias de armazenamento (Figuras 1a e 1b).

As uvaias embaladas apresentaram menor perda de massa comparado com aquelas sem embalagem (Tabela 1), apresentando em média 3,71 e $0,44 \%$ quando embaladas em PVC e CF film respectivamente e 8,46 sem embalagem. Sob temperatura ambiente, as uvaias armazenadas sem embalagem apresentaram perda de massa 1,8 e 9 vezes maior que naquelas em PVC e CF film respectivamente, enquanto que sob refrigeração as perdas foram de 1,7 e 51,4 vezes maior, embora o tempo de armazenamento sob refrigeração, tenha sido três vezes maior, evidenciando o efeito da embalagem na redução da perda de massa das frutas. Essa diferença pode ser devida ao grau de permeabilidade da embalagem à água e aos gases.

Esse resultado sugere que a embalagem associada à refrigeração proporcionou uma taxa transpiratória menor dos frutos ao manter uma maior umidade relativa no ambiente e menor atividade respiratória nos frutos, os quais, quando armazenados sob refrigeração por 12 dias, apresentaram proporcionalmente menor perda de massa que aquelas sob temperatura ambiente.

CARVALHO \& LIMA (2002) observaram, em sua revisão, que a perda de massa tem efeitos sobre a fisiologia dos tecidos vegetais, podendo antecipar a maturação e a senescência de frutos tropicais. Essa perda depende do tempo de armazenamento e da transpiração. A perda de água é a causa principal da deterioração, resultando não somente em perdas quantitativas, mas também na 

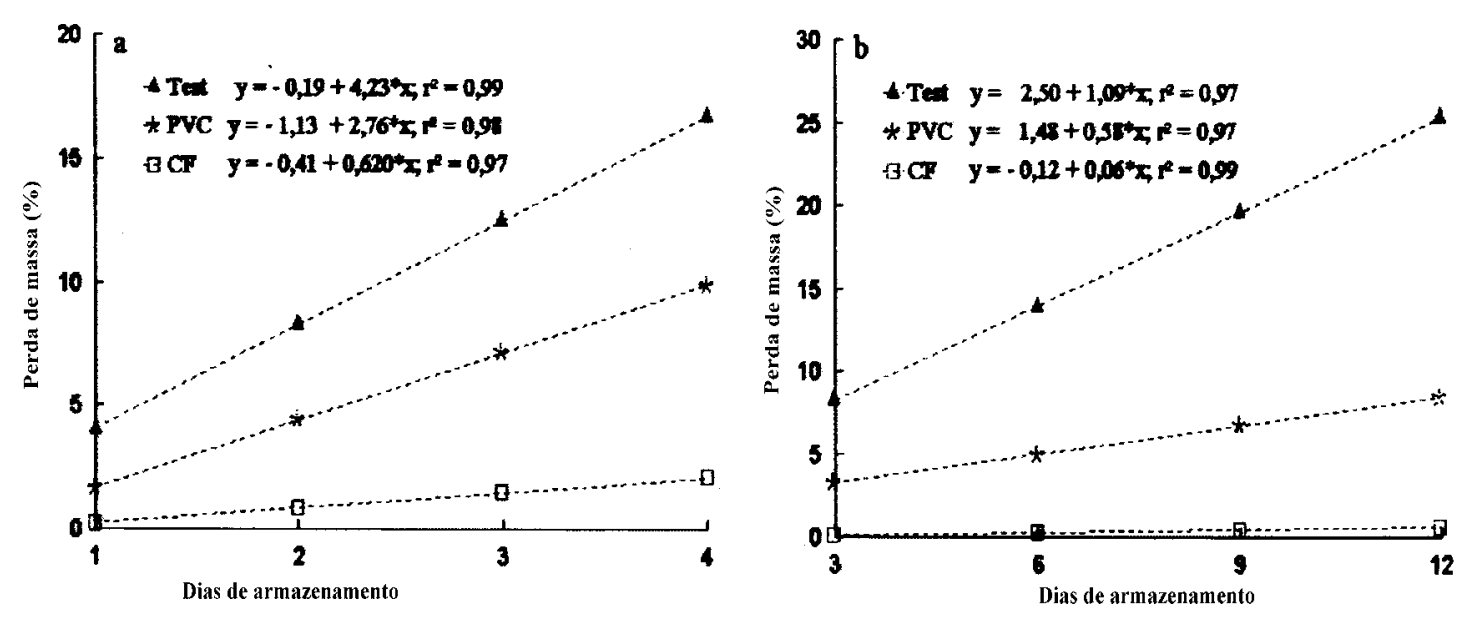

Figura 1 - Perda de massa de uvaias armazenadas sem embalagem, em embalagem de PVC e em CF film sob temperatura ambiente $30 \pm 2^{\circ} \mathrm{C}$ (a) e refrigeração $13 \pm 2^{\circ} \mathrm{C}$ (b).

aparência, causando o murchamento e enrugamento, na qualidade textural (amaciamento e perda de frescor e suculência) e em qualidade nutricional.

O teor de sólidos solúveis totais não variou significativamente entre as embalagens, porém, apresentou valores médios mais altos nas uvaias sob temperatura ambiente $\left(6,59{ }^{\circ} \mathrm{Brix}\right)$. O teor médio de SST $\left(6,2^{\circ} \mathrm{Brix}\right)$, neste trabalho, encontrase abaixo daquele observado por DONADIO (1997). Provavelmente as condições de clima e de cultivo podem ter influenciado nessa resposta.

$\mathrm{O}$ pH e a acidez também não variaram significativamente entre os tipos de embalagens utilizadas,

Tabela1 - Perda de massa e teor de sólidos solúveis totais (SST) de uvaias armazenadas.

\begin{tabular}{lcccc}
\hline Embalagem & $\begin{array}{c}\text { Ambiente } \\
\text { (4 dias) }\end{array}$ & Temperatura refrigeração (12 dias) \\
\hline & \multicolumn{4}{c}{ Perda de massa (\%) } \\
\hline Testemunha & 6,53 & $\mathrm{Ab}$ & 10,64 & $\mathrm{Aa}$ \\
PVC & 3,603 & $\mathrm{Ba}$ & 3,81 & $\mathrm{Ba}$ \\
CF film & 0,73 & $\mathrm{Ca}$ & 0,21 & $\mathrm{Cb}$ \\
\hline & & & $\mathrm{SST}^{\circ} \mathrm{Brix}$ & \\
\hline Testemunha & 7,26 & $\mathrm{a}$ & 6,73 & $\mathrm{~b}$ \\
PVC & 6,40 & $\mathrm{a}$ & 5,31 & $\mathrm{~b}$ \\
CF film & 6,12 & $\mathrm{a}$ & 5,40 & $\mathrm{~b}$ \\
\hline
\end{tabular}

Médias seguidas de mesma letra maiúscula na coluna e minúscula na linha são estatísticamente iguais entre si pelo teste de Tukey a $5 \%$ de probabilidade de erro. à temperatura e o tempo de armazenamento, com médias de 2,87 (pH) e 3,98\% (ATT) respectivamente.

Sob refrigeração, os frutos testemunha apresentaram elevação do pH acompanhada da ATT, o que poderá ser explicado pela maior perda de água observada nessa condição, contribuindo assim, para concentrar os ácidos orgânicos presentes no suco celular e elevar aparentemente a acidez, uma vez que, baseado em revisão realizada por CALEGANO et al. (2002), os ácidos orgânicos tendem a diminuir durante o amadurecimento dos frutos, em virtude de sua utilização como substrato respiratório.

Os sintomas de murcha sob temperatura ambiente foram observados aos três dias de armazenamento para as uvaias sem embalagem; sob refrigeração, foram observados aos nove dias para as uvaias sem embalagem, e doze dias para PVC e CF film. As frutas testemunha já não apresentavam qualidade comercial aos quatro e doze dias sob ambiente e refrigeração, respectivamente.

Embora os atributos químicos dos frutos não tenham apresentado variação significativa entre as embalagens, mas, considerando que a aparência murcha dos frutos pode inviabilizar sua comercialização in natura, o investimento em embalagens pode garantir um produto de melhor qualidade, principalmente se o produto for comercializado com base no peso.

As uvaias embaladas conservaram a aparência e qualidade para comercialização quando armazenadas até quatro dias sob temperatura de $30 \pm 2^{\circ} \mathrm{C}$ e 
12 dias em refrigeração a $13 \pm 2^{\circ} \mathrm{C}$.

\section{REFERÊNCIASBIBLIOGRAFICAS}

ALVES, R.E. Acerola (Malpighia emarginata D.C.) fisiologia da maturação e armazenamento refrigerado sob atmosfera modificada. 1993. 99p. Dissertação (Mestrado) - ESAL.

ANDERSEN, O.; ANDERSEN, V.U. As frutas silvestres brasileiras. 2.ed. Rio de Janeiro : Edições Globo, 1988. 203p.

AOAC Official methods analysis of the association of official analytical chemistry. Washington, DC, 1992. p.1015

CALEGARO, J.M. et al. Utilização de atmosfera modificada na conservação de morangos em pós-colheita. Pesquisa Agropecuária Brasileira, v.37, n.8, p.1049-1055, 2002.

CARVALHO, P.R.N. Análises de vitaminas em alimentos: manual técnico. Campinas : Instituto de Tecnologia de alimentos, 1988. 108p.

CARVALHO, A.V.; LIMA, L.C.O. Qualidade de kiwi minimamente processados e submetidos a tratamentos com ácido ascórbico, ácido cítrico e cloreto de cálcio. Pesquisa
Agropecuária Brasileira, v.37, n.5, p.679-685, 2002.

ChitarRa, M.I.F.; CHITARRA, A.B. Pós-colheita de frutos e hortaliças: fisiologia e manuseio. Lavras : ESAL/ FAEPE, 1990. 320p.

DONADIO, L.C. Study of some Brazilian Myrtaceae in Jaboticabal - SP. Acta Horticulturae, v.452, p.181-183, 1997.

LI, C.: KADER, A.A. Residual effects of controlled atmospheres on postharvest physiology and quality of strawberries. Journal American Horticultural Science, v.114, n.4, p.629-634. 1989.

MAZARO, S.M. et al. Qualidade de kiwi armazenado em duas temperaturas sob atmosfera controlada e com eliminação de etileno. Ciência Rural, v.30, n.6, p.947-952, 2000

MELO NETO, M.L. et al. Utilização de embalagens plásticas e refrigeração na conservação da manga (Mangifera indica L.) cv. Palmer. Revista Brasileira de Fruticultura, v.21, n.2, p.160-165, 1999

SCALON, S.P.Q. et al. Conservação de morangos (Fragaria ananassa Duch.) cv. Sequóia em atmosfera modificada. Revista Brasileira de Fruticultura, v.18, n.3, p.431-436, 1996. 